\title{
Pathogenesis of Acanthamoeba Keratitis
}

\author{
Noorjahan Panjwani, PhD \\ Departments of Ophthalmology and Biochemistry, and The New England Eye Center, Tufts \\ University School of Medicine, Boston, Massachusetts
}

\section{Abstract}

Acanthamoeba keratitis (AK) is a serious infection of the cornea. At present, diagnosis of the disease is not straightforward and treatment is very demanding. While contact lens wear is the leading risk factor for AK, Acanthamoeba parasites are increasingly recognized as an important cause of keratitis in non-contact lens wearers. The first critical step in the pathogenesis of infection is the adhesion of the microbe to the surface of the host tissues. Acanthamoebae express a major virulence protein, the mannose-binding protein (MBP), which mediates the adhesion of amoebae to the surface of the cornea. The MBP is a transmembrane protein with characteristics of a typical cell surface receptor. Subsequent to the MBP-mediated adhesion to host cells, the amoebae produce a contact-dependent metalloproteinase and several contact-independent serine proteinases. These proteinases work in concert to produce a potent cytopathic effect (CPE) involving killing of the host cells, degradation of epithelial basement membrane and underlying stromal matrix, and penetration into the deeper layers of the cornea. In the hamster animal model, oral immunization with the recombinant MBP protects against $\mathrm{AK}$, and this protection is associated with an increased level of anti-MBP IgA in tears of protected animals. Normal human tear fluid contains IgA antibodies against Acanthamoeba MBP that is likely to provide protection by inhibiting the adhesion of parasites to host cells. Indeed, in in vitro CPE assays, even a low concentration of tears (10 [MU] $\mu \mathrm{L}$ of undiluted tears per milliliter of media) almost completely inhibits Acanthamoeba-induced CPE. In addition to adherence-inhibiting, IgA-mediated protection, human tears also contain IgA-independent factors that provide protection against Acanthamoeba-induced CPE by inhibiting the activity of cytotoxic proteinases. Characterization of the CPE-inhibitory factors of human tears should lead to a better understanding of the mechanism by which the tissues of the host resist the infection and also help decode circumstances that predispose to Acanthamoeba infections.

\section{Keywords}

Acanthamoeba keratitis; cytotoxic proteinases; lectin; mannose-binding protein; tear fluid

\section{Introduction}

Acanthamoeba keratitis (AK) is a serious, debilitating, and intensely painful infection of the cornea caused by parasites of the genus Acanthamoeba.${ }^{1-7}$ If it is not diagnosed early and treated aggressively, extensive ocular damage can occur, and enucleation may be required. At present, diagnosis of the disease is not straightforward, ${ }^{8-10}$ and treatment of AK is very demanding. While hourly, around-the-clock, aggressive treatment involving the use of three

Single-copy reprint requests to: Dr. Noorjahan Panjwani (address below). Corresponding Author: Dr. Noorjahan Panjwani,

Department of Ophthalmology, Tufts University School of Medicine, 136 Harrison Avenue, Boston, MA 02111. Tel: 617-636-6776.

Fax: 617-636-0348. Noorjahan.panjwani@tufts.edu..

The author has no commercial or proprietary interest in any concept or product discussed in this article. 
or more drugs can bring the disease under control, often patients must be treated for months, and, in some cases, extensive treatment must be continued for over a year. Despite the aggressive treatment, occasionally, the disease fails to respond, and some patients discontinue therapy because of intolerable burning with medication instillation. ${ }^{8}$

While contact lens wear is the leading risk factor for AK, ${ }^{11-13}$ Acanthamoeba parasites are increasingly recognized as an important cause of keratitis in non-contact lens wearers, $14^{-} 17$ and, recently, AK was reported in a 5-year old boy without a history of contact lens usage or trauma.14 The incidence of contact lens-related AK is still unclear, but it has been estimated that one in 300-1500 contact lens wearers may develop some form of AK over a 30-year period of contact lens wearing. ${ }^{7}$ During the years 2003-2008, a substantial increase ( $\sim$ fourfold) in the incidence of AK was noted in the U.S., as well as in a number of other countries. ${ }^{18-} 20$ This rise has been associated, at least in part, to a specific contact lens formulation.20 Also, Joslin and coworkers have suggested that a recent outbreak of AK in the Chicago, Illinois area could be, in part, due to EPA-mandated reduction in chlorine use for municipal water treatment plants. 21

The first critical step in the pathogenesis of infection is the adhesion of the microbe to the surface of the host tissues. In many cases, initial interactions between the microbe and the host are mediated by a carbohydrate-mediated recognition system. The cell surface of all eukaryotic cells is decorated with glycoproteins, which are constituted of oligosaccharides attached to a protein backbone. The oligosaccharide chains are constituted of a number of sugars, including hexoses (eg, mannose and galactose), pentoses (eg, fucose), hexosamines (eg, glucosamine and galactosamine) and sialicacids. The saccharide residues of the oligosaccharides are well known for their role in mediating host-parasite interactions leading to the development of infections. For example, Cryptosporidium, as well as Entamoeba parasite, which cause diarrheal diseases, attach and invade the host cells by interactions between distinct galactose-specific carbohydrate-binding proteins expressed on the surface of the parasites and glycoproteins containing galactose residues on the surface of host cells. 22,23 Similarly, uropathogenic $E$. coli also adhere and invade the host cells via a carbohydrate-based recognition system. ${ }^{24-26}$

In recent years, significant progress has been made toward understanding the mechanism by which Acanthamoebae adhere to the host cells, a key first step in the pathogenesis of infection. These studies have revealed that a major virulence protein of Acanthamoeba is a mannose-binding protein that mediates the adhesion of amoebae to the surface of the cornea and also plays a role in events that occur subsequent to the adhesion and lead to the development of a devastating cytopathic effect (CPE).

\section{Acanthamoeba Mannose-Binding Protein (MBP)}

Acanthamoeba MBP has been isolated from membrane extracts of parasites by affinity chromatography on mannose-affinity columns and has been characterized with respect to its structure and role in the pathogenesis of AK. ${ }^{27-30}$ The MBP is a $400-\mathrm{kDa}$ protein that is composed of multiple 130-kDa subunits. It binds to mannose, but not to a number of other closely related saccharides, including mannosamine and mannitol. The lectin is constituted of a large N-terminal extracellular domain, a transmembrane domain, and a short C-terminal cytoplasmic domain, and has characteristics of a typical cell surface receptor. ${ }^{28}$ In general, lectins bind to the specific carbohydrate residues via their carbohydrate recognition domains (CRDs). Many lectins contain a single CRD, whereas some lectins contain multiple CRDs with distinct differences in fine specificity and affinity for saccharides. Acanthamoeba MBP is believed to contain a novel CRD, as it lacks sequence identity to well-characterized lectin CRDs. The size, location, and the number of CRDs in the amoeba MBP remain to be 
determined. Functional studies have shown that Acanthamoeba MBP is a major virulence protein that not only mediates the adhesion of amoebae to the surface of the cornea, but also plays a role in the induction of a cytopathic effect.

\section{The Role of MBP in the Adhesion of Acanthamoeba to Host Cells}

Multiple studies have contributed to the concept that Acanthamoebae MBP mediates the adhesion of the amoebae to the surface of cornea. Many of these studies have utilized free mannose to compete with the sugar-binding site of the MBP and inhibit its function. These studies have shown that Acanthamoebae bind to corneal epithelial cells as well to the surface of corneal buttons, and this binding is inhibited if the adhesion assays are performed in the presence of free [ALPHA] $\alpha$-mannose, but not by a variety of other noncompeting saccharides (Figure 1). ${ }^{31-33}$ Also, Acanthamoebae bind to purified mannose-containing glycoproteins of corneal epithelial cells, as well as to a neoglycoprotein, mannosylatedbovine serum albumin (Man-BSA), but not to galactose-BSA (Figure 2). ${ }^{33}$

Finally, pathogenic potential of parasites in vitro is directly correlated with the expression level of the MBP. ${ }^{30}$ Pathogenic strains of Acanthamoeba, which produce robust amounts of MBP, bind to host cells and produce amoeba-induced cytopathic effects in a mannosedependent manner. In contrast, nonpathogenic strains, which produce little or no MBP, do not bind to host cells or produce CPE. ${ }^{30}$ Together, these findings demonstrate that one of the mechanisms of Acanthamoeba adhesion to the corneal surface involves interactions between the MBP on the surface of Acanthamoeba and mannose-containing glycoproteins (mannose-GPs) on the corneal surface.

\section{The Role of MBP in Acanthamoeba-Induced Cytopathic Effect}

As described earlier, the adhesion of parasites to the host cells is the critical first step in the pathogenesis of infection. Subsequent to the MBP-mediated adhesion, parasites produce a potent CPE involving killing of the host cells, degradation of epithelial basement membrane and underlying stromal matrix, and penetration into the deeper layers of the cornea. In the in vitro CPE assays, when monolayer cultures of corneal epithelial cells are incubated with amoebae, within a few hours, small cell-free plaques are seen in the monolayers. With the continued incubation with the amoebae, the size of the cell-free areas increases, eventually resulting in almost complete loss of the cell layer (Figure 3). ${ }^{33}$ As regards the molecular mechanism of CPE, it is known that the CPE results from killing of host cells and destruction of ECM by proteinases secreted by amoebae. ${ }^{33-42}$ In vitro studies have demonstrated that culture conditions can have significant influence on the nature of proteases produced by amoebae and that zymography profiles of proteases produced by pathogenic and nonpathogenic strains are distinct.

Although contact-independent factors contribute to the amoeba-induced CPE, it is clear that dynamic MBP-mediated host-parasite interactions leading to the secretion of contactdependent factors, ie, the virulence factors that are secreted subsequent to the adhesion of the parasite to the host cells, play a highly significant role in the pathogenesis of amoebainduced CPE. Kinear et al have compared Acanthamoeba-induced CPE on host cells in the presence and in the absence of physical contact, using transwell culture plates. ${ }^{43}$ They demonstrated that target cell damage in the absence of physical contact is much slower, requiring 7-10 days for destruction of greater than $75 \%$ of the monolayer, whereas only 24 hours were required for complete destruction of the monolayer when cocultures were incubated without the filter inserts, permitting direct physical contact between the amoebae and the target cells. 
Efforts to characterize the significance of mannose-mediated host-parasite interactions in amoeba-induced CPE have revealed that all mannose-based saccharides that inhibit amoebabinding to corneal epithelial cells also inhibit 1) amoeba-induced cytolysis of host cells as measured by ${ }^{51} \mathrm{Cr}$ release assays, and 2) amoeba-induced $\mathrm{CPE}$ as measured by in vitro $\mathrm{CPE}$ assays (Figure 4A, group: [ALPHA] $\alpha-$ Man). ${ }^{33}$

Subsequent to the mannose-mediated adhesion of parasite to the host cells, the amoebae produce a cytotoxic metalloproteinase (P3) (Figure 4B, lane E+A) that is not produced if either host cells (Figure 4B, lane EM) or parasites (Figure4B, lane ACM) are incubated alone. Also, a metalloproteinase inhibitor, Galardin, inhibits Acanthamoeba-induced CPE in a dose-dependent manner (Cao and Panjwani, unpublished). These findings, in conjunction with the studies showing that if the secretion of the metalloproteinase P3 is inhibited by blocking the adhesion of parasites to host cells, amoeba-induced CPE does not ensue (Figure $4 \mathrm{~A}),{ }^{33}$ suggest that $\mathrm{P} 3$ plays a critical role in the amoeba-induced CPE. Also, subsequent to the adhesion of amoebae to host cells, the expression of an amoebic serine proteinase (P2) is markedly upregulated (Figure 4B, lane E+A) ${ }^{33}$ However, unlike P3, which is not produced if amoebae are prevented from adhering to host cells by adding mannose to the co-culture (Figure $4 \mathrm{~B}$, lane $\mathrm{E}+\mathrm{A}+\mathrm{M}$ ), upregulation of $\mathrm{P} 2$ occurs regardless of whether or not mannose is present in the coculture.

In addition, Niederkorn and colleagues ${ }^{34-38}$ have shown that the Acanthamoebae, when incubated in culture media containing free mannose, induce the secretion of a cytotoxic proteinase, which they referred to as mannose-induced protein (MIP)133. MIP-133, which exhibits molecular weight of $133-\mathrm{kDa}$ on polyacrylamide gels, 38 comigrates with the proteinase P2 as a 98-kDa component on gelatin zymography gels (Panjwani, Alizadeh and Niederkorn, unpublished data). It is known that molecular masses cannot be accurately determined in gelatin-containing SDS-PAGE gels for a variety of reasons, including sieving effect of gelatin and affinity interactions between gelatin and the active site of enzyme. ${ }^{44}$ Thus, it is possible that P2 and MIP133 may be the same component. That both the metalloproteinase P3 and the serine proteinase MIP133/P2 work in concert in the induction of $\mathrm{CPE}$ is suggested by studies demonstrating that 1 ) the amoeba-induced CPE does not ensue either, if the activity of $\mathrm{P} 3$ is inhibited by a metalloproteinase inhibitor (Galardin) or, if the secretion of $\mathrm{P} 3$ is inhibited by adding mannose to the co-culture in the in vitro CPE assays, (Figure 4A, group: [ALPHA] $\alpha-M a n),{ }^{33}$ and 2) serine proteinase inhibitors, as well as an anti-MIP133, inhibit amoeba-induced CPE.33,37

Most likely, the MBP-mediated adhesion of amoeba to the target cells triggers a cellsignaling cascade that leads to the release of the proteinases via regulated exocytosis. In this respect, it is well established that cytoskeletal elements, and especially Rho signaling and/or $\mathrm{Ca}^{++}$channels, play a role in the regulated secretion of metalloproteinases, as well as in exocytosis of hormones and neurotransmitters. ${ }^{45-48}$ That signal transduction events and cytoskeletal elements of amoebae indeed play a role in amoeba-induced CPE is suggested by studies showing that cytochalasin $\mathrm{D}$, which disrupts cytoskeletal function, Beridel, which inhibits $\mathrm{Ca}^{++}$channels, and phorbol ester PMA, which stimulates PKC, all inhibit Acanthamoeba-induced CPE. ${ }^{49}$ As described earlier, Acanthamoeba MBP is a transmembrane protein with characteristics of a typical cell surface receptor. ${ }^{28}$ It is constituted of a large $\mathrm{N}$-terminal extracellular domain, a transmembrane domain, and a short C-terminal cytoplasmic domain (Figure 5A). Indeed, the cytoplasmic domain (CT) of MBP has the potential to participate in cell-signaling events, because it contains a number of phosphorylation sites and also an NPLF motif (Figure 5B). The NPLF motif is identical to the one present in the cytoplasmic tail of chicken and human [BETA] $\beta 2$ integrins and is known for its ability to participate in cell-signaling events leading to cell spreading and shape change.${ }^{50-} 52$ Thus, it is reasonable to hypothesize that subsequent to the adhesion of 
Acanthamoeba to the surface of the cornea via the CRD of the MBP, a cascade of signal transduction events begins via the CT domain of MBP, leading to the expression and/or secretion of P3, MIP133 and possibly other, hitherto unidentified cytotoxins; this, in turn, produces the CPE.

In summary, the MBP-mediated dynamic host-parasite interactions lead to the secretion of metallo- and serine-proteinases, which work in concert to produce the CPE. Signal transduction events mediated by the cytoplasmic domain of the MBP are thought to play a role in amoeba-induced CPE by triggering the secretion of contact-dependent cytotoxic proteinases.

\section{Acanthamoeba MBP and Immunobiology of AK}

Given that over 25 million individuals in the U.S. alone wear contact lenses and the amoebae are ubiquitously distributed in the environment, one wonders why the occurrence of AK is not much higher. A reasonable answer is that protective factors must be present in vivo. Both innate and acquired immune systems are thought to play a role in providing protection against $\mathrm{AK} .^{53}$

\section{A. Acquired Immunity}

Seminal studies by Niederkorn and coworkers have suggested that, specifically, the mucosal immune mechanism plays an instrumental role in providing immunity to primary AK. ${ }^{54-56}$ Using pig and hamster animal models, these authors have shown that in response to intramuscular injections of Acanthamoeba antigens, the hosts develop high titer serum IgG antibodies. ${ }^{54-56}$ However, despite this, the animals are not protected against the ocular infection. In contrast, animals immunized by an oral administration of the amoeba antigen were protected against multiple ocular challenges with infectious parasites. ${ }^{54,55,57-59}$ The animals that were protected did not exhibit high titer IgG serum antibodies, but rather possessed parasite-specific IgA in the tears, intestinal wash, and stool samples that inhibited the adhesion of parasites to host cells.

1. Protective Role of Anti-MBP IgA-In the hamster animal model, oral immunization with recombinant Acanthamoeba MBP protects against Acanthamoeba keratitis, and this protection is associated with an increased level of anti-MBP IgA in tears of protected animals (Figure 6). ${ }^{27}$ The presence of increased levels of anti-MBP IgA in tears of immunized animals is likely to provide protection by inhibiting the adhesion of parasites to host cells. In this respect, it is important to note that normal human mucosal secretions, including tears, saliva, and breast milk, all contain IgA antibodies against Acanthamoeba MBP (Garate, Cao and Panjwani, unpublished).

Based on the concept that anti-MBP IgA antibodies in tear fluid of normal individuals should provide protection by inhibiting the adhesion of parasite to host cells, studies were conducted to determine whether normal tear fluid inhibits Acanthamoeba-induced CPE in vitro. In this study, the presence of even a low concentration of tears $(10[\mathrm{MU}] \mu \mathrm{L}$ of undiluted tears per milliliter of media) almost completely inhibited Acanthamoeba-induced CPE (Figure 7) ${ }^{60}$ The CPE was inhibited by pretreatment of the parasites with tears. In contrast, the pretreatment of host cells with tears was not protective. ${ }^{60}$ This finding suggests that the target of the inhibitory factor is the parasite. Since even 1:10 diluted tear fluid has the capacity to inhibit the amoeba-induced CPE, the importance of tears in providing protection against $\mathrm{AK}$ is obvious in the natural setting in which undiluted tears would be available to block the adhesion. 
2. Role of IgA-Independent Protective Factors-We aimed to determine whether human tears, in addition to providing adherence-inhibiting, IgA-mediated protection, also contain IgA-independent factors that may provide protection against AK. We, therefore, tested IgA-depleted human tear fluid for its ability to inhibit Acanthamoeba-induced CPE. We demonstrated that IgA-depleted tears inhibit the amoeba-induced CPE, but unfractionated complete tears are three times more potent in inhibiting the amoeba-induced $\mathrm{CPE}$ than the IgA-depleted tears. ${ }^{60}$ Additional studies using breast milk as a model of human mucosal secretions revealed that the IgA-depleted milk also inhibited the Acanthamoeba-induced CPE. ${ }^{61}$ IgA-depleted milk proteins were fractionated into four major fractions (F1 to F4) by gel filtration on Sephadex G200. Of these four fractions, the CPE-inhibitory activity was detected largely in fraction F3, which contained components ranging in molecular weight up to 500-kDa. In contrast, fractions F1, F2, and F4 lacked CPE-inhibitory activity. Moreover, fraction F3 but not F1, F2, or F4, inhibited amoebic proteinases. ${ }^{61}$

The above data, in conjunction with published findings showing that amoebic proteinases are responsible for the induction of Acanthamoeba CPE, suggest that human mucosal secretions have the potential to provide protection against Acanthamoeba-induced CPE by an additional mechanism that is independent of $\operatorname{IgA}$ and involves, at least in part, the inhibition of cytotoxic proteinases of amoebae. The presence of IgA-dependent, as well as the IgA-independent, CPE-inhibitory factors in tears helps us understand why the incidence of $A K$ is low. Their presence in nonocular secretions help to explain, at least in part, why almost all nonocular tissues are resistant to Acanthamoeba infections in healthy individuals. Characterization of the CPE-inhibitory factors of human mucosal secretions, such as milk, tears, and saliva, should lead to a better understanding of the mechanism by which the tissues of the host resist the infection and also help decipher circumstances that predispose to Acanthamoeba infections.

Considering that tear fluid is highly protective against Acanthamoeba-induced CPE in vitro, it would be important to determine whether tear fluid of AK patients lacks protective factors against the Acanthamoeba parasites. In this respect, Alizadeh et al have reported that tears of AK patients contain significantly reduced levels of Acanthamoeba-specific IgA compared to the tears of healthy individuals. ${ }^{62}$ Based on these findings, the authors suggested that AK patients may have an immunological "blind-spot" that prevents them from mounting an effective immune response against Acanthamoeba. Studies in my laboratory are currently underway to determine whether tear fluid of AK patients lacks IgA antibodies against specific epitopes of MBP. If AK patients lack protective IgA antibodies, then, the following points should be considered:

1. Should $A K$ be a bilateral disease? In fact, it appears that patients who develop AK in one eye are at a higher risk of developing AK in the other eye. ${ }^{63-67} \mathrm{~A}$ recent review of $45 \mathrm{AK}$ patients revealed $10 \%$ of the cases to be bilateral. ${ }^{67}$ This number is far higher than the estimated incidence of $\mathrm{AK}$ in the general population. Moreover, it is known that two major risk factors in the pathogenesis of $\mathrm{AK}$ are minor corneal trauma and exposure to contaminated solution. Also, in animal models, corneal surface injury is prerequisite for development of AK. ${ }^{68}$ Thus, in the absence of corneal trauma, the contralateral eye may not develop AK.

2. Why do AK patients not develop Acanthamoeba infection at nonocular sites? This may be because the IgA-independent protective system described above, involving the inhibition of cytotoxic proteinases of amoebae by components of mucosal secretions, may be more protective in nonocular tissues where such secretion is plentiful (eg, saliva and intestine) compared to tear fluid. 


\section{B. Innate Immunity}

The human complement system plays a critical role in the innate immune system. ${ }^{69,70}$ Its major role is to recognize and promote clearance of invading microorganisms by phagocytosis or lysis. The first step in the activation of the complement system is the cleavage of $\mathrm{C} 3$ into $\mathrm{C} 3 \mathrm{a}$ and $\mathrm{C} 3 \mathrm{~b}$ by $\mathrm{C} 3$ convertase enzyme and the deposition of $\mathrm{C} 3 \mathrm{~b}$ onto the microbial target. Subsequently, the microbe is recognized and engulfed via the $\mathrm{C} 3 \mathrm{~b}$ receptors on the surface of the phagocytic cells of the immune system. Deposited C3b may also participate in the creation of $\mathrm{C} 5$ convertase enzymes that lead to the formation of the membrane attack complex (MAC), which inserts into the cell membrane of the invading organism, causing microbial cell lysis. While many organisms are susceptible, some are resistant to complement lysis. ${ }^{71-78}$ Although macrophages and neutrophils may have a potential to provide defense against $\mathrm{AK},{ }^{79-81}$ it is known that pathogenic Acanthamoebae are resistant to complement lysis. A thorough study by Toney and Marciano-Cabral ${ }^{76}$ using three different Acanthamoebae species (A. polyphaga, A. castellanii, and A. culbertsoni) showed that: 1) Acanthamoebae parasites have the ability to deplete the hemolytic complement activity from normal human serum and, yet, they resist the complementmediated cellular lysis; and 2) the most pathogenic specie is the most complement-resistant.

It is known that proteins of the complement pathway, as well as complement regulatory factors, are present in cornea, ${ }^{82-84}$ as well as in tear, ${ }^{85}$ but little is known about the role of specific proteins of the complement pathway in the pathogenesis of AK. Since the vast majority of proteins of complement pathway are mannose-containing glycoproteins, ${ }^{86}$ they may bind to Acanthamoeba MBP and influence the innate immune system of the host. In this respect, we have determined that complement $\mathrm{C} 3$ binds to the MBP on the surface of the amoebae via a mannose-based recognition (Cao and Panjwani, unpublished). It is, thus, conceivable that subsequent to the binding to MBP, $\mathrm{C} 3$ is internalized and depleted, resulting in the evasion of the host immune system. Such a hypothesis is particularly applicable in the infections involving the cornea, because, despite the fact that the complement system is active in tear, concentration of most complement proteins in tear, including that of $\mathrm{C} 3$, is much lower than in serum (1\% to $4 \%$ compared to serum85), and the concentration may be even lower within the stroma. 84 The complement proteins may, therefore, be prone to depletion if internalized by the parasite.

\section{What is the Potential of MBP in Modulating Encystment?}

The life cycle of Acanthamoeba comprises two distinct stages, trophozoite and cyst. The trophozoite is flat and irregular in shape and measures 20-40 [MU] $\mu \mathrm{m}$. Under favorable environmental conditions, the trophozoite undergoes mitosis and is capable of phagocytosing bacteria and yeast. A cyst is formed from a trophozoite when adverse conditions, such as exposure to biocidal agents, starvation, elevated temperature, and hyperosmolarity, prevail. Acanthamoeba cysts are frequently seen in the corneal stroma of patients with established Acanthamoeba keratitis. Since cysts are highly resistant to treatment with biocidal agents and are able to survive harsh conditions, they can persist into the stroma through the course of treatment and may excyst when the conditions become favorable, with the concomitant return of robust infection. The greatest challenge in the management of the AK remains the effective eradication of cysts, which are resistant to most of the anti-microbial drugs. Clearly, an understanding of the stimuli that trigger encystations of Acanthamoeba will aid in the eventual design of strategies to interrupt the parasite's life cycle and thereby prevent recurrent infection.

Whether Acanthamoeba MBP plays a role in the process of encystment is not known. It is known that that encystment of Acanthamoeba is associated with the down-regulation of $\mathrm{MBP}^{30}$ and with the concomitant loss of the ability of the encysted parasite to bind to host 
cells and produce in vitro CPE. It is noteworthy that the galactose-specific lectin of Entamoeba, a different parasite that produces infection of the gut, plays a role in encystment of parasite in addition to its well-known role in mediating the adhesion of the parasite to host cells and the pathogenicity of the parasite.

Eichinger and colleagues have delineated sequential steps in the process of encystment of Entamoeba ${ }^{87-89}$ According to their findings, subsequent to the nutrient deprivation and hypo-osmotic stress, the trophozoites aggregate and then undergo encystment. If the aggregation is stopped by adding free galactose, the encystment does not ensue. The aggregation of trophozoites is mediated by precise amounts of polyvalent galactoseterminated molecules. It is thought that these molecules cluster galectin lectin on the trophozoites' surface, and these clusters, in turn, promote aggregation of trophozoites and subsequent encystment.

According to one model ${ }^{90}$ of Entamoeba encystment in the gut, initially, the parasite binds to the colonic mucus layer and locally depletes the mucus layer. During depletion of the mucus layer, a critical concentration of mucin is generated that clusters the galactosespecific lectin on the trophozoites' cell surface, and subsequent binding of catecholamines by the trophozoites triggers the encystment process. Indeed, it would be important to investigate to what extent, if any, MBP-mediated signals play a role in encystment of Acanthamoeba parasites.

As mentioned earlier, during the years 2003 to 2008, a substantial increase ( four-fold) in the incidence of AK was noted in a number of countries, including the Unites States. This rise has been associated at least in part with the use of Complete Moisture Plus multipurpose solution, which induces the encystment of Acanthamoeba parasites into immature cysts. ${ }^{91} \mathrm{It}$ would be interesting to determine if the mannose-containing multivalent glycoproteins are shed from the surface of trophozoites during incubation with Complete Moisture Plus and, if so, whether these glycoproteins, at a critical concentration, clusterize and cross-link MBP lectin on the amoebae surface. The lectin clusters, if present on the surface of immature cysts, are likely to enhance the pathogenic potential of the parasites by promoting their adhesion to host cell surface.

\section{Summary and Conclusions}

The studies summarized herein highlight the recent progress that has been made in the elucidation of the molecular mechanism of AK. It has been demonstrated that Acanthamoebae express a major virulence protein, the mannose-binding protein (MBP) that mediates the adhesion of amoebae to the surface of the cornea. The MBP-mediated dynamic host-parasite interactions lead to the secretion of metallo- and serine-proteinases, which work in concert to produce potent cytopathic effect (CPE). Normal tear fluid contains highly potent protective factors against Acanthamoeba-induced CPE. These protective factors include both anti-MBP IgA that inhibits adhesion of amoebae to host cells, and IgAindependent factors that inhibit the activity of cytotoxic proteinases. Future studies should be aimed at characterizing the CPE-inhibitory factors of human tears and determining whether tear fluid and other mucosal secretions of AK patients contain reduced levels of IgA-dependent and/or IgA-independent protective factors. Such studies should lead to a better understanding of the mechanism by which the tissues of the host resist the infection, and should also help decode circumstances that predispose to Acanthamoeba infections.

Two major challenges in the management of AK continue to be difficulty in the diagnosis of the disease and effective eradication of cysts, which are resistant to most of the antimicrobial drugs. Since MBP has unique Acanthamoebae-specific amino acid sequence, it 
should be possible, in the future, to develop PCR- and antibody-based methods to aid in the diagnosis of the disease. No doubt, it would be important to determine whether MBP, like the galactose-specific lectin of Entamoeba, plays a role in the encystment of Acanthamoebae. Clearly, an understanding of the stimuli that trigger encystation ofAcanthamoeba will aid in the eventual design of strategies to interrupt the parasite's life cycle and thereby prevent recurrent infection.

While a great deal has been discovered, it only serves to highlight that we are still firmly on the tip of the iceberg in terms of understanding why, in healthy, competent individuals, only cornea is susceptible to invasion by Acanthamoebae, and why, despite the ubiquitous distribution of the parasite, the incidence of AK is relatively low. Ongoing efforts in different laboratories will help to unravel the complexities of glycobiology and immunobiology in the pathogenesis of AK.

\section{Acknowledgments}

I am greatly indebted to my long-time colleague and a senior Research Associate in the lab, Dr. Zhiyi Cao, who performed many of the studies described in this review and also trained all postdoctoral fellows and students who undertook studies on Acanthamoeba keratitis in the author's laboratory. I would also like to take this opportunity to thank my mentor, Dr. Jules Baum. I have learned much from him and, indeed, it is a number of discussions with him that led me to begin the fruitful journey on the investigation of Acanthamoeba keratitis.

Supported by the National Institutes of Health Grant EY09349, the Massachusetts Lions Eye Research Fund, the New England Corneal Transplant Research Fund; and a challenge grant from Research to Prevent Blindness to the New England Eye Center.

\section{References}

1. Awwad ST, Petroll WM, McCulley JP, Cavanagh HD. Updates in Acanthamoeba keratitis. Eye Contact Lens. 2007; 33:1-8. [PubMed: 17224672]

2. Chong EM, Dana MR. Acanthamoeba keratitis. Int Ophthalmol Clin. 2007; 47:33-46. [PubMed: 17450005]

3. Clarke DW, Niederkorn JY. The pathophysiology of Acanthamoeba keratitis. Trends Parasitol. 2006; 22:175-80. [PubMed: 16500148]

4. Foulks GN. Acanthamoeba keratitis and contact lens wear: static or increasing problem? Eye Contact Lens. 2007; 33(6 Pt 2):412-4. discussion 414-5. [PubMed: 17975435]

5. Hammersmith KM. Diagnosis and management of Acanthamoeba keratitis. Curr Opin Ophthalmol. 2006; 17:327-31. [PubMed: 16900022]

6. Marciano-Cabral F, Cabral G. Acanthamoeba spp. as agents of disease in humans. Clin Microbiol Rev. 2003; 16:273-307. [PubMed: 12692099]

7. Mathers WD. Acanthamoeba: a difficult pathogen to evaluate and treat. Cornea. 2004; 23:325. [PubMed: 15097123]

8. Hargrave SL, McCulley JP, Husseini Z, Brolene Study Group. Results of a trial of combined propamidine isethionate and neomycin therapy for Acanthamoeba keratitis. Ophthalmology. 1999; 106:952-7. [PubMed: 10328395]

9. Khan NA. Acanthamoeba: biology and increasing importance in human health. FEMS Microbiol Rev. 2006; 30:564-95. [PubMed: 16774587]

10. Parmar DN, Awwad ST, Petroll WM, et al. Tandem scanning confocal corneal microscopy in the diagnosis of suspected acanthamoeba keratitis. Ophthalmology. 2006; 113:538-47. [PubMed: 16581415]

11. Cohen EJ, Fulton JC, Hoffman CJ, et al. Trends in contact lens-associated corneal ulcers. Cornea. 1996; 15:566-70. [PubMed: 8899267]

12. Seal DV. Acanthamoeba keratitis update-incidence, molecular epidemiology and new drugs for treatment. Eye (Lond). 2003; 17:893-905. [PubMed: 14631394] 
13. Stehr-Green JK, Bailey TM, Visvesvara GS. The epidemiology of Acanthamoeba keratitis in the United States. Am J Ophthalmol. 1989; 107:331-6. [PubMed: 2929702]

14. Demirci G, Ay GM, Karabas LV, et al. Acanthamoeba keratitis in a 5-year-old boy without a history of contact lens usage. Cornea. 2006; 25:356-8. [PubMed: 16633040]

15. Illingworth CD, Cook SD, Karabatsas CH, Easty DL. Acanthamoeba keratitis: risk factors and outcome. Br J Ophthalmol. 1995; 79:1078-82. [PubMed: 8562539]

16. Sharma S, Srinivasan M, George C. Acanthamoeba keratitis in non-contact lens wearers. Arch Ophthalmol. 1990; 108:676-8. [PubMed: 2334324]

17. Srinivasan M, Burman S, George C, Nirmalan PK. Non-contact lens related Acanthamoeba keratitis at a tertiary eye care center in south India: Implications for eye care programs in the region. Med Sci Monit. 2003; 9:CR125-9. [PubMed: 12709670]

18. Cavanagh HD. Acanthamoeba keratitis: 2007: a train wreck in slow motion. Eye Contact Lens. 2007; 33:209. [PubMed: 17873621]

19. Acharya NR, Lietman TM, Margolis TP. Parasites on the rise: a new epidemic of Acanthamoeba keratitis. Am J Ophthalmol. 2007; 144:292-3. [PubMed: 17659960]

20. (CDC) CfDCaP. Acanthamoeba keratitis multiple states, 2005-2007. MMWR Morb Mortal Wkly Rep. 2007; 56:3.

21. Joslin CE, Tu EY, McMahon TT, et al. Epidemiological characteristics of a Chicago-area Acanthamoeba keratitis outbreak. Am J Ophthalmol. 2006; 142:212-7. [PubMed: 16876498]

22. Bhat N, Joe A, PereiraPerrin M, Ward HD. Cryptosporidium p30, a galactose/Nacetylgalactosamine-specific lectin, mediates infection in vitro. J Biol Chem. 2007; 282:34877-87. [PubMed: 17905738]

23. Frederick JR, Petri WA Jr. Roles for the galactose-/N-acetylgalactosamine-binding lectin of Entamoeba in parasite virulence and differentiation. Glycobiology. 2005; 15:53R-59R.

24. Abraham SN, Sun D, Dale JB, Beachey EH. Conservation of the D-mannose-adhesion protein among type 1 fimbriated members of the family Enterobacteriaceae. Nature. 1988; 336(6200): 682-4. [PubMed: 2904657]

25. Jones CH, Pinkner JS, Roth R, et al. FimH adhesin of type 1 pili is assembled into a fibrillar tip structure in the Enterobacteriaceae. Proc Natl Acad Sci U S A. 1995; 92:2081-5. [PubMed: 7892228]

26. Krogfelt KA, Bergmans H, Klemm P. Direct evidence that the FimH protein is the mannosespecific adhesin of Escherichia coli type 1 fimbriae. Infect Immun. 1990; 58:1995-8. [PubMed: 1971261]

27. Garate M, Alizadeh H, Neelam S, et al. Oral immunization with Acanthamoeba castellanii mannose-binding protein ameliorates amoebic keratitis. Infect Immun. 2006; 74:7032-4. [PubMed: 16982837]

28. Garate M, Cao Z, Bateman E, Panjwani N. Cloning and characterization of a novel mannosebinding protein of Acanthamoeba. J Biol Chem. 2004; 279:29849-56. [PubMed: 15117936]

29. Garate M, Cubillos I, Marchant J, Panjwani N. Biochemical characterization and functional studies of Acanthamoeba mannose-binding protein. Infect Immun. 2005; 73:5775-81. [PubMed: 16113295]

30. Garate M, Marchant J, Cubillos I, et al. In vitro pathogenicity of Acanthamoeba is associated with the expression of the mannose-binding protein. Invest Ophthalmol Vis Sci. 2006; 47:1056-62. [PubMed: 16505041]

31. Morton LD, McLaughlin GL, Whiteley HE. Effects of temperature, amebic strain, and carbohydrates on Acanthamoeba adherence to corneal epithelium in vitro. Infect Immun. 1991; 59:3819-22. [PubMed: 1894379]

32. Yang Z, Cao Z, Panjwani N. Pathogenesis of Acanthamoeba keratitis: carbohydrate-mediated hostparasite interactions. Infect Immun. 1997; 65:439-45. [PubMed: 9009294]

33. Cao Z, Jefferson DM, Panjwani N. Role of carbohydrate-mediated adherence in cytopathogenic mechanisms of Acanthamoeba. J Biol Chem. 1998; 273:15838-45. [PubMed: 9624184]

34. Alizadeh H, Neelam S, Hurt M, Niederkorn JY. Role of contact lens wear, bacterial flora, and mannose-induced pathogenic protease in the pathogenesis of amoebic keratitis. Infect Immun. 2005; 73:1061-8. [PubMed: 15664950] 
35. Alizadeh H, Neelam S, Niederkorn JY. Effect of immunization with the mannose-induced Acanthamoeba protein and Acanthamoeba plasminogen activator in mitigating Acanthamoeba keratitis. Invest Ophthalmol Vis Sci. 2007; 48:5597-5604. [PubMed: 18055809]

36. Alizadeh H, Pidherney MS, McCulley JP, Niederkorn JY. Apoptosis as a mechanism of cytolysis of tumor cells by a pathogenic free-living amoeba. Infect Immun. 1994; 62:1298-1303. [PubMed: 8132336]

37. Hurt M, Neelam S, Niederkorn J, Alizadeh H. Pathogenic Acanthamoeba spp secrete a mannoseinduced cytolytic protein that correlates with the ability to cause disease. Infect Immun. 2003; 71:6243-55. [PubMed: 14573643]

38. Hurt M, Niederkorn J, Alizadeh H. Effects of mannose on Acanthamoeba castellanii proliferation and cytolytic ability to corneal epithelial cells. Invest Ophthalmol Vis Sci. 2003; 44:3424-31. [PubMed: 12882791]

39. Khan NA, Jarroll EL, Panjwani N, et al. Proteases as markers for differentiation of pathogenic and nonpathogenic species of Acanthamoeba. J Clin Microbiol. 2000; 38:2858-61. [PubMed: 10921939]

40. Kim WT, Kong HH, Ha YR, et al. Comparison of specific activity and cytopathic effects of purified $33 \mathrm{kDa}$ serine proteinase from Acanthamoeba strains with different degree of virulence. Korean J Parasitol. 2006; 44:321-30. [PubMed: 17170574]

41. Pettit DA, Williamson J, Cabral GA, Marciano-Cabral F. In vitro destruction of nerve cell cultures by Acanthamoeba spp.: a transmission and scanning electron microscopy study. J Parasitol. 1996; 82:769-77. [PubMed: 8885887]

42. van Klink F, Alizadeh H, Stewart GL, et al. Characterization and pathogenic potential of a soil isolate and an ocular isolate of Acanthamoeba castellanii in relation to Acanthamoeba keratitis. Curr Eye Res. 1992; 11:1207-20. [PubMed: 1490339]

43. Kinnear FB. Cytopathogenicity of acanthamoeba, vahlkampfia and hartmannella: quantative and qualitative in vitro studies on keratocytes. J Infect. 2003; 46:228-37. [PubMed: 12799148]

44. Hummel KM, Penheiter AR, Gathman AC, Lilly WW. Anomalous estimation of protease molecular weights using gelatin-containing Sds-Page. Anal Biochem. 1996; 233:140-2. [PubMed: 8789159]

45. Abecassis I, Olofsson B, Schmid M, et al. RhoA induces MMP-9 expression at CD44 lamellipodial focal complexes and promotes HMEC-1 cell invasion. Exp Cell Res. 2003; 291:363-76. [PubMed: 14644158]

46. Lecuona E, Ridge K, Pesce L, et al. The GTP-binding protein RhoA mediates Na,K-ATPase exocytosis in alveolar epithelial cells. Mol Biol Cell. 2003; 14:3888-97. [PubMed: 12972572]

47. Norman JC, Price LS, Ridley AJ, Koffer A. The small GTP-binding proteins, Rac and Rho, regulate cytoskeletal organization and exocytosis in mast cells by parallel pathways. Mol Biol Cell. 1996; 7:1429-42. [PubMed: 8885237]

48. Turner NA, O'Regan DJ, Ball SG, Porter KE. Simvastatin inhibits MMP-9 secretion from human saphenous vein smooth muscle cells by inhibiting the RhoA/ROCK pathway and reducing MMP-9 mRNA levels. FASEB J. 2005; 19:804-6. [PubMed: 15728660]

49. Taylor WM, Pidherney MS, Alizadeh H, Niederkorn JY. In vitro characterization of Acanthamoeba castellanii cytopathic effect. J Parasitol. 1995; 81:603-9. [PubMed: 7623204]

50. Calderwood DA, Fujioka Y, de Pereda JM, et al. Integrin beta cytoplasmic domain interactions with phosphotyrosine-binding domains: a structural prototype for diversity in integrin signaling. Proc Natl Acad Sci U S A. 2003; 100:2272-7. [PubMed: 12606711]

51. Calderwood DA, Yan B, de Pereda JM, et al. The phosphotyrosine binding-like domain of talin activates integrins. J Biol Chem. 2002; 277:21749-58. [PubMed: 11932255]

52. Kaapa A, Peter K, Ylanne J. Effects of mutations in the cytoplasmic domain of integrin beta(1) to talin binding and cell spreading. Exp Cell Res. 1999; 250:524-34. [PubMed: 10413605]

53. Niederkorn JY. Innate and adaptive immune responses to ocular Acanthamoeba infection. Expert Rev Ophthalmol. 2008; 3:8.

54. Niederkorn JY. The role of the innate and adaptive immune responses in Acanthamoeba keratitis. Arch Immunol Ther Exp (Warsz). 2002; 50:53-9. [PubMed: 11916309] 
55. Niederkorn JY, Alizadeh H, Leher HF, McCulley JP. The immunobiology of Acanthamoeba keratitis. Springer Semin Immunopathol. 1999; 21:147-60. [PubMed: 10457588]

56. Van Klink F, Leher H, Jager MJ, et al. Systemic immune response to Acanthamoeba keratitis in the Chinese hamster. Ocul Immunol Inflamm. 1997; 5:235-44. [PubMed: 9455740]

57. Leher H, Kinoshita K, Alizadeh H, et al. Impact of oral immunization with Acanthamoeba antigens on parasite adhesion and corneal infection. Invest Ophthalmol Vis Sci. 1998; 39:2337-43.

[PubMed: 9804142]

58. Leher HF, Alizadeh H, Taylor WM, et al. Role of mucosal IgA in the resistance to Acanthamoeba keratitis. Invest Ophthalmol Vis Sci. 1998; 39:2666-73. [PubMed: 9856776]

59. Niederkorn JY, Alizadeh H, Leher H, et al. Role of tear anti-acanthamoeba IgA in Acanthamoeba keratitis. Adv Exp Med Biol. 2002; 506(Pt B):845-50. [PubMed: 12614001]

60. Cao Z, Saravanan C, Goldstein MH, et al. Effect of human tears on acanthamoeba-induced cytopathic effect. Arch Ophthalmol. 2008; 126:348-52. [PubMed: 18332314]

61. Saravanan C, Cao Z, Kumar J, et al. Milk components inhibit Acanthamoeba-induced cytopathic effect. Invest Ophthalmol Vis Sci. 2008; 49:1010-5. [PubMed: 18326724]

62. Alizadeh H, Apte S, El-Agha MS, et al. Tear IgA and serum IgG antibodies against Acanthamoeba in patients with Acanthamoeba keratitis. Cornea. 2001; 20:622-7. [PubMed: 11473164]

63. Bernauer W, Duguid GI, Dart JK. Early clinical diagnosis of acanthamoeba keratitis. A study of 70 eyes. Klin Monbl Augenheilkd. 1996; 208:282-4. In French. [PubMed: 8766027]

64. Donoso R, Mura JJ, Lopez M. Acanthamoeba keratitis treated with propamidine and polyhexamethyl biguanide (PHMB). Rev Med Chil. 2002; 130:396-401. In Spanish. [PubMed: 12090104]

65. Nakano E, Oliveira M, Portellinha W, et al. Confocal microscopy in early diagnosis of Acanthamoeba keratitis. J Refract Surg. 2004; 20(5 Suppl):S737-740. [PubMed: 15521280]

66. Tseng CH, Fong CF, Chen WL, et al. Overnight orthokeratology-associated microbial keratitis. Cornea. 2005; 24:778-82. [PubMed: 16160491]

67. Wilhelmus KR, Jones DB, Matoba AY, et al. Bilateral acanthamoeba keratitis. Am J Ophthalmol. 2008; 145:193-7. [PubMed: 18222188]

68. van Klink F, Alizadeh H, He Y, et al. The role of contact lenses, trauma, and Langerhans cells in a Chinese hamster model of Acanthamoeba keratitis. Invest Ophthalmol Vis Sci. 1993; 34:1937-44. [PubMed: 8491547]

69. Ogundele M. Role and significance of the complement system in mucosal immunity: particular reference to the human breast milk complement. Immunol Cell Biol. 2001; 79:1-10. [PubMed: 11168616]

70. Rus H, Cudrici C, Niculescu F. The role of the complement system in innate immunity. Immunol Res. 2005; 33:103-12. [PubMed: 16234578]

71. Gutierrez-Kobeh L, Cabrera N, Perez-Montfort R. A mechanism of acquired resistance to complement-mediated lysis by Entamoeba histolytica. J Parasitol. 1997; 83:234-41. [PubMed: 9105303]

72. Marciano-Cabral F, Cabral GA. The immune response to Naegleria fowleri amebae and pathogenesis of infection. FEMS Immunol Med Microbiol. 2007; 51:243-59. [PubMed: 17894804]

73. Petri WA Jr, Haque R, Mann BJ. The bittersweet interface of parasite and host: lectin-carbohydrate interactions during human invasion by the parasite Entamoeba histolytica. Annu Rev Microbiol. 2002; 56:39-64. [PubMed: 12142490]

74. Toney DM, Marciano-Cabral F. Alterations in protein expression and complement resistance of pathogenic Naegleria amoebae. Infect Immun. 1992; 60:2784-90. [PubMed: 1319405]

75. Toney DM, Marciano-Cabral F. Membrane vesiculation of Naegleria fowleri amoebae as a mechanism for resisting complement damage. J Immunol. 1994; 152:2952-9. [PubMed: 8144894]

76. Toney DM, Marciano-Cabral F. Resistance of Acanthamoeba species to complement lysis. J Parasitol. 1998; 84:338-44. [PubMed: 9576508]

77. Whiteman LY, Marciano-Cabral F. Susceptibility of pathogenic and nonpathogenic Naegleria spp. to complement-mediated lysis. Infect Immun. 1987; 55:2442-7. [PubMed: 3653986] 
78. Whiteman LY, Marciano-Cabral F. Resistance of highly pathogenic Naegleria fowleri amoebae to complement-mediated lysis. Infect Immun. 1989; 57:3869-75. [PubMed: 2807551]

79. Clarke DW, Alizadeh H, Niederkorn JY. Intracorneal instillation of latex beads induces macrophage-dependent protection against Acanthamoeba keratitis. Invest Ophthalmol Vis Sci. 2006; 47:4917-25. [PubMed: 17065507]

80. Hurt M, Apte S, Leher H, et al. Exacerbation of Acanthamoeba keratitis in animals treated with anti-macrophage inflammatory protein 2 or antineutrophil antibodies. Infect Immun. 2001; 69:2988-95. [PubMed: 11292716]

81. Marciano-Cabral F, Toney DM. The interaction of Acanthamoeba spp. with activated macrophages and with macrophage cell lines. J Eukaryot Microbiol. 1998; 45:452-8. [PubMed: 9703682]

82. Bora NS, Gobleman CL, Atkinson JP, et al. Differential expression of the complement regulatory proteins in the human eye. Invest Ophthalmol Vis Sci. 1993; 34:3579-84. [PubMed: 7505007]

83. Jha P, Bora PS, Sohn JH, et al. Complement system and the eye. Adv Exp Med Biol. 2006; 586:53-62. [PubMed: 16893064]

84. Mondino BJ, Ratajczak HV, Goldberg DB, et al. Alternate and classical pathway components of complement in the normal cornea. Arch Ophthalmol. 1980; 98:346-9. [PubMed: 6766301]

85. Willcox MD, Morris CA, Thakur A, et al. Complement and complement regulatory proteins in human tears. Invest Ophthalmol Vis Sci. 1997; 38:1-8. [PubMed: 9008624]

86. Ritchie GE, Moffatt BE, Sim RB, et al. Glycosylation and the complement system. Chem Rev. 2002; 102:305-20. 19. [PubMed: 11841245]

87. Cho J, Eichinger D. Crithidia fasciculata induces encystation of Entamoeba invadens in a galactose-dependent manner. J Parasitol. 1998; 84:705-10. [PubMed: 9714198]

88. Coppi A, Eichinger D. Regulation of Entamoeba invadens encystation and gene expression with galactose and N-acetylglucosamine. Mol Biochem Parasitol. 1999; 102:67-77. [PubMed: 10477177]

89. Eichinger D. A role for a galactose lectin and its ligands during encystment of Entamoeba. J Eukaryot Microbiol. 2001; 48:17-21. [PubMed: 11249188]

90. Eichinger D. Encystation in parasitic protozoa. Curr Opin Microbiol. 2001; 4:421-6. [PubMed: 11495805]

91. Kilvington S, Heaselgrave W, Lally JM, et al. Encystment of Acanthamoeba during incubation in multipurpose contact lens disinfectant solutions and experimental formulations. Eye Contact Lens. 2008; 34:133-9. [PubMed: 18463477] 


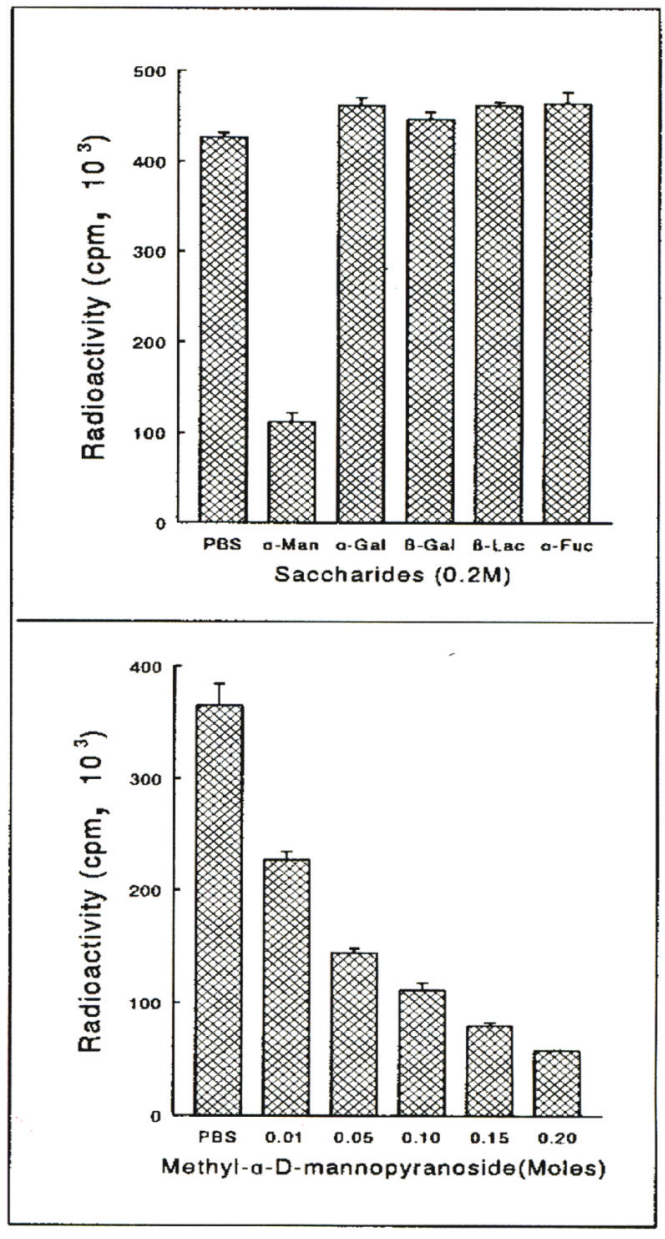

Figure 1.

Acanthamoeba binding assay showing that [ALPHA] $\alpha$-Man, but not other saccharides, inhibit adhesion of amoebae to confluent cultures of rabbit corneal epithelium. Confluent cultures of corneal epithelium in 48 -well culture plates were incubated with ${ }^{35} \mathrm{~S}$-labeled Acanthamoebae in PBS. Of the five saccharides tested, only [ALPHA] $\alpha$-Man inhibited the adhesion of amoebae to the monolayer culture of corneal epithelium (top). The inhibitory effect of [ALPHA] $\alpha$-Man on the adhesion of amoebae to epithelial cells was dosedependent (bottom). Similar results were obtained when adhesion assays were performed using corneal buttons instead of monolayer cultures. These data suggest that Amoebae bind to the surface of corneas by a mannose-mediated recognition, implying the existence of a mannose receptor on one cell type and binding to the mannose residues of glycoproteins on the other cell type. (Reprinted with permission from Yang Z ET al.32) 


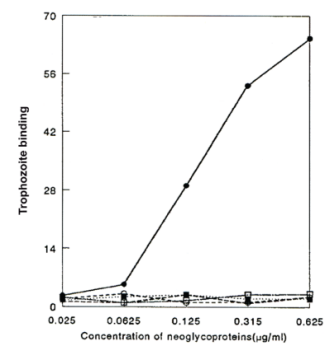

Figure 2.

Amoebae bind to Man-BSA but not to other neoglycoproteins. ${ }^{35} \mathrm{~S}$-Labeled amoebae were allowed to bind to microtiter wells coated with increasing amounts of various neoglycoproteins. $\bullet$, mannose-BSA (Man-BSA);,$N$-acetyl-D-glucosamine-BSA; $\triangle$, fucose-BSA; $\boldsymbol{n}$, galactose-BSA; $\square, N$-acetyl-D-galactosamine-BSA. Mean values are reported ( $n=6$ in each group). (Reprinted with permission from Cao Z ET al.33) 

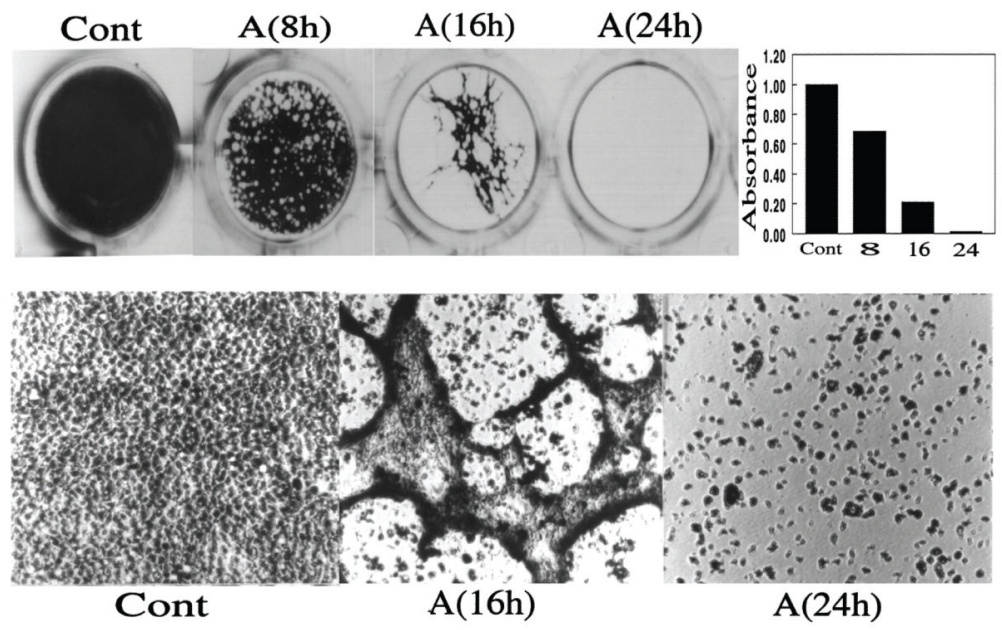

Figure 3.

Acanthamoeba-induced cytopathic effect. Acanthamoebae $\left(2 \times 10^{5}\right.$ parasites $\left./ \mathrm{ml}\right)$ were added to confluent cultures of corneal epithelium in 24-well plates, and the cultures were incubated in a $\mathrm{CO}_{2}$ incubator for varying periods. At the end of the incubation period, the plates were stained with Giemsa and photographed. Top panel shows the photographs of the wells and lower panel shows the light micrographs of representative areas. Approximate cell density in each well, as measured by scanning the plates in a computer-assisted Bio-Image scanner, is shown in the top right panel. A value of 1.0 was assigned to the cell density of the plates incubated in media alone (Cont.). The values for cultures incubated with amoebae are expressed as change in the density with respect to control plates. Note that during the early phase $(8 \mathrm{~h})$, small cell-free plaques appeared in the monolayer; with continued incubation, the size of cell-free areas increased $(16 \mathrm{~h})$, and eventually monolayer surrounding the large plaques lifted entirely from the culture dish, resulting in almost complete loss of the cell layer. (Reprinted with permission from Cao Z ET al.33) 

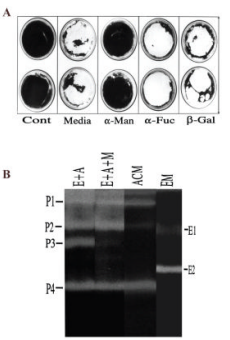

Figure 4.

A. [ALPHA] $\alpha$-Man inhibits Acanthamoeba-induced cytopathic effect. Confluent corneal epithelial cultures in 6-well plates were incubated overnight with Acanthamoebae in the presence or absence of various saccharides. The plates were then stained with Giemsa. Clear, unstained regions indicate loss of cells. Dark, stained areas indicate presence of cells. Note that epithelial cells incubated with amoebae in media alone were destroyed almost completely during overnight incubation (Media). Methyl $\alpha$-mannopyranoside ([ALPHA] $\alpha$ Man) markedly inhibited the amoeba-induced CPE whereas [ALPHA] $\alpha$-L-fucose ([ALPHA] $\alpha$-Fuc) and [BETA] $\beta$-galactose ([BETA] $\beta$-Gal) had little effect. Cont. epithelial cells incubated in media alone without amoebae. B: Zymography of culture media collected from wells shown in Panel A: (i) epithelial cells with amoeba (E+A), (ii) epithelial cells with amoeba in the presence of mannose $(\mathrm{E}+\mathrm{A}+\mathrm{M})$, (iii) epithelial cells alone (EM), or (iv) amoeba alone (ACM).Reprinted with permission from $\mathrm{Cao} \mathrm{Z}$ et al.33). 


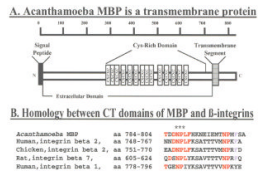

Figure 5.

MBP cDNA codes for a precursor protein of 833 amino acids. Analysis of the deduced amino acid sequence using various programs revealed that residues $1-21$ correspond to the MBP signal peptide and that amoeba MBP is a transmembrane protein (Panel A) containing a 712 amino acid long N-terminal extracellular (EC) domain (residues 22-733), a 22 amino acid long transmembrane domain (residues 734-755) and a short, 78 amino acid long, $\mathrm{C}$ terminal cytoplasmic (CT) domain. The CT domain of MBP contains an NPLF motif that is identical to the one present in the cytoplasmic tail of chicken and human [beta] $\beta 2$ integrins and is similar to the NPXY motif that is present in a number of other integrins (Panel B, red). The motifs NPLF/NPXY have been shown to bind to a number of intracellular proteins including talin, Dab, and tensin and play a key role in integrin activation and cell signaling events leading to stable cell adhesion, growth control and cell spreading. (Top panel reprinted with permission from Garate $\mathrm{M}$ et al.21) 


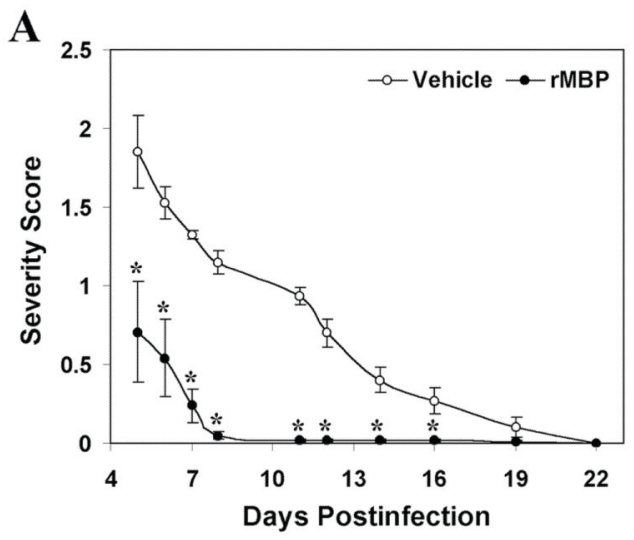

B

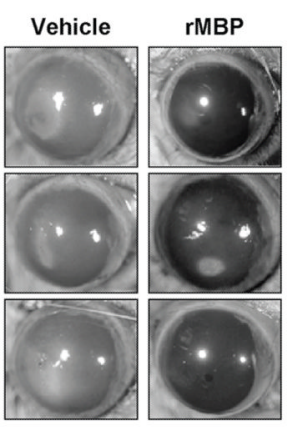

Figure 6.

Immunization of Chinese hamsters with rMBP ameliorates amoebic keratitis. (A) Hamsters were orally immunized with $\mathrm{rMBP}(100[\mathrm{MU}] \mu \mathrm{g})$ and were challenged with A. castellaniiinfected contact lenses. The severity of infection was recorded beginning on postinfection day 5. The severity score was significantly lower for the rMBP-immunized group (solid circles) than for the sham-immunized control group (open circles). Data are presented as means \pm standard errors ( $n=6$ for each group). (B) Representative photographs of eyes on postinfection day 12. * $P<0.05$ compared to control group. (Reprinted with permission from Garate M ET al.27) 

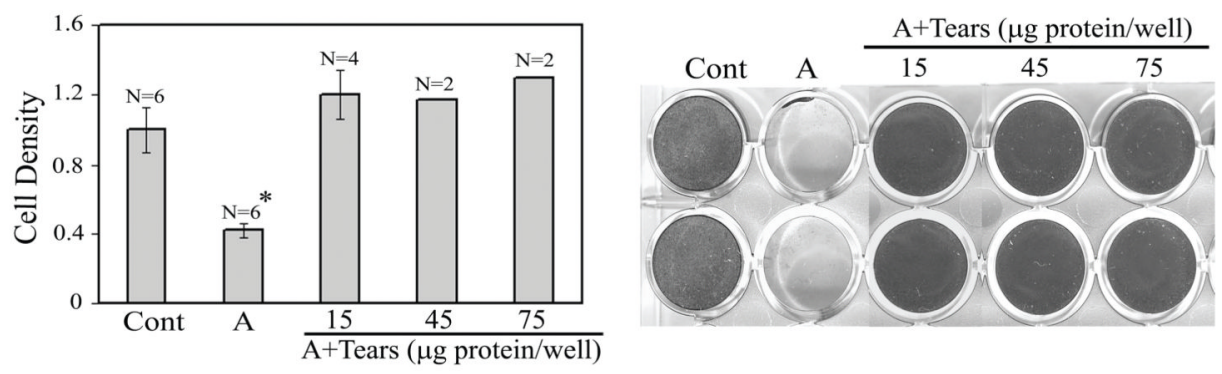

Figure 7.

Human tears inhibit Acanthamoeba-induced cytopathic effect. . Epithelial cells were incubated overnight alone (Cont) or with Acanthamoebae in the absence (A) or presence (A +tears) of pooled tear fluid. At the end of the incubation period, the monolayers were stained with Giemsa, photographed and scanned to estimate approximate cell density. Clear, unstained regions indicate loss of epithelial cells; dark, stained areas indicate presence of cells. A value of 1.0 was assigned to the cell density of the plates incubated in media alone without amoebae (Cont). The values for cultures incubated in the presence of tears are expressed as the change in the density with respect to control plates. $* P<.05$ compared with all other groups. Data are expressed as mean $\pm \mathrm{SE}(\mathrm{n}=4$ or 6 per group except for 45 - and $75-\mu \mathrm{g} /$ well groups, where $\mathrm{n}=2$ owing to limited availability of tear samples). Representative photographs of the plates are shown in the right panel. For A+tears, the number of micrograms of protein per well indicates tear protein concentration used for the assay. (Reprinted with permission from Cao Z ET al.60) 